\title{
A data support infrastructure for Clean Development Mechanism forestry implementation: an inventory perspective from Cameroon
}

\author{
Peter A. Minang • Michael K. McCall • \\ Margaret M. Skutsch · Jeroen J. Verplanke
}

Received: 15 August 2006/ Accepted: 26 January 2007 / Published online: 21 February 2007

(C) Springer Science+Business Media B.V. 2007

\begin{abstract}
Clean Development Mechanism (CDM) forestry project development requires highly multi-disciplinary and multiple-source information that can be complex, cumbersome and costly to acquire. Yet developing countries in which CDM projects are created and implemented are often data poor environments and unable to meet such complex information requirements. Using Cameroon as an example, the present paper explores the structure of an enabling host country data support infrastructure for CDM forestry implementation, and also assesses the supply potential of current forestry information. Results include a conceptual data model of CDM project data needs; the list of meso- and macro-level data and information requirements (Demand analysis); and an inventory of relevant data available in Cameroon (Supply analysis). From a comparison of demand and supply, we confirm that data availability and the relevant infrastructure for data or information generation is inadequate for supporting carbon forestry at the micro, meso and macro-levels in Cameroon. The results suggest that current CDM afforestation and reforestation information demands are almost impenetrable for local communities in host countries and pose a number of cross-scale barriers to project adoption. More importantly, we identify proactive regulatory, institutional and capacity building policy strategies for forest data management improvements that could enhance biosphere carbon management uptake in poor countries. CDM forestry information research needs are also highlighted.
\end{abstract}

Keywords Cameroon - Clean Development Mechanism · Data infrastructure · Land use $\cdot$ land use change and forestry $\cdot$ Cameroon

P. A. Minang $(\bowtie) \cdot$ M. K. McCall · J. J. Verplanke

International Institute for Geo-Information Science and Earth Observation (ITC), P. O. Box 6, 7500 AA Enschede, Netherlands

e-mail: minang@itc.nl

M. M. Skutsch

Technology and Sustainable Development (TSD), University of Twente, P. O. Box 217, 7500

AE Enschede, Netherlands 


\section{Introduction}

The Clean Development Mechanism (CDM) is one of the "flexible mechanisms" in the Kyoto Protocol designed to accomplish the objectives of the United Nations Framework Convention for Climate Change-(UNFCCC). CDM makes provision for investment by industrialised countries and industry in carbon emissions reduction and carbon sequestration projects in developing countries. These projects should contribute to sustainable development in developing countries (Non-Annex 1) while enabling developed countries (Annex 1) to meet emission limitation targets. One way in which sustainable development might be achieved could be through forestry projects, which are managed by and for rural communities, where they would contribute to local environmental values as well as income.

Land Use, Land Use Change and Forestry-(LULUCF) projects must meet certain conditions in order to acquire Certified Emission Reductions (CERs). CERs represent the emission reduction outputs of projects and constitute the basis on which payments are made. Projects must fulfil specific criteria in order to be issued CERs, including eligibility, additionality, acceptability in terms of environmental and social impacts, sustainable development, and leakage. Fulfilment of these requirements implies the provision of reliable, documented and archived evidence demonstrating adherence to these criteria. A close examination of CDM information requirements reveal a fuzzy, highly multi-disciplinary and multiple-source mix which can be very complex, cumbersome and costly to acquire (Pfaff et al. 2000). Yet developing countries in which these projects are created and implemented are known to be data poor environments in very many domains (Dalal-Clayton et al. 2003).

Such data/information scarcity and unreliability in developing countries inhibit the abilities for community uptake and implementation of CDM forestry projects, thereby excluding poor communities from payments for environmental services and envisaged sustainable development benefits. More specifically, information scarcity could limit the scope for bottom-up estimates of carbon balance for forestry options (Conant and Paustian 2004). Yet little attention has been given to enhancing host country and project level information management.

The objectives of this paper are 3-fold. First, it explores and underlines the need for an enabling data infrastructure for terrestrial carbon mitigation projects. Secondly, it reviews land use and forestry information available at the micro, meso and macro-levels in the context of community forestry in Cameroon, as an example of a potential CDM host country, and considers potential sources and ways of enhancing information management for CDM project uptake and management. Finally, it looks briefly at the new developments as regards forest policy under UNFCCC Reduced Emissions from Deforestation and Degradation (REDD), and considers what implications this would have for the data infrastructure.

Data/Information infrastructure is defined as the relevant base collection of technologies, policies and institutional arrangements that facilitate the availability of and access to data relevant for the implementation of the CDM. It could include a set of structured or semi-structured data collected and stored in a proprietary format (data collection) and also, a formalised set of properties that describe with significant amount of detail the characteristics of the contents of a data collection (metadata) (Morales 2004). Such an infrastructure provides the basis for the discovery, 
evaluation and application of data and information, potentially enabling reduced data collection time and cost, duplication, and greater access. "Data" are those facts about the world which an organization or individual appreciates as being meaningful to their concern; while "information" is data which may have been processed, and that is appreciated as useful within a particular decision-making process (Lewis 1994).

\section{Methods and context}

This study borrows principally from information and planning science methods. We use Grounded Theory in the analysis of information systems as described in Urquhart (2001) and Strauss and Corbin (1990). The method utilises an analytic process by which concepts are identified and developed in terms of their properties. We categorized, coded, compared and related CDM information requirements from policy documents and commentary in literature. The result in this case is a conceptual data model in the form of an integrative diagram representing the CDM data needs (Demand analysis). Similar methods are employed to determine the availability of such relevant data in Cameroon (Supply analysis).

To structure the analysis of the data supply infrastructure in a useful way, a Strengths, Weaknesses, Opportunities and Threats (SWOT) analysis (Weihrich 1982) was made. In this instance, we categorised, coded, compared and related information from interview transcripts, field observation/office data inventory notes and secondary data. The results also include a set of possible strategies for data and information supply enhancement needed to enable CDM forestry project uptake and implementation.

These methods are applied to two case studies of community forestry at the micro-level and to government represented by the Ministry of Forests and Fauna at the regional (provincial) and the national level (meso and macro, respectively). Given the very hierarchical and centralised nature of the government and governance in Cameroon, we have chosen to deal with both the meso and macro-levels as one. The two communities studied at the micro-level are Tinto and Bimbia Bonadikombo, in the southwest province of the country.

Cameroon has not as yet submitted any community forestry projects under the CDM. The two case studies represent typical community forestry projects with typical levels of data availability, which could potentially be submitted as CDMs. These cases thus give a good idea of what sorts of data demands can be met at present, and what would further be required. Learning from their experiences with data for community forestry purposes sheds light on what the likely information management problems and opportunities would be for carbon forestry.

The micro-level study context: local community forest initiatives

\section{The Tinto community}

The Tinto community consists of three neighbouring villages of the same clan namely Tinto Bessinghe, Tinto Kerieh and Tinto Mbu, in descending order of size. The total population is estimated at 1700 with less than $1 \%$ of the population being non-native. Tinto is rural but has the status of a sub-divisional (sub-district) 
headquarters. Inhabitants are mostly farmers, often combining farming with forest extraction activities.

The community signed a management agreement with government on a 1295 ha evergreen humid forest in December 2002, after receiving some technical assistance and financial support from a non-governmental organisation (NGO), Living Earth Foundation. The Tinto Clan Community Forest Common Initiative Group and a forest manager run the forest on behalf of the community. Few activities written into the management plan have been implemented. Lack of funds, the remoteness of the community and leadership inadequacies have been advanced among the reasons for this inertia.

\section{The Bimbia Bonadikombo community}

The Bimbia Bonadikombo community is partly peri-urban in character and located on the fringes of the Limbe (Victoria) urban community. Limbe and the surrounding areas have a population of about 123,900 inhabitants. It is highly heterogeneous with few local people (of the Bakweri tribe), making the social and cultural environment complex. It is a complex of many villages and several plantation worker camps.

The community has been managing a 3700 ha forest since mid-2002, with some technical support from the Mount Cameroon Project, which assisted particularly in preparing a forest inventory. The Bimbia Bonadikombo Natural Resource Management Council manages the forest. An executive board runs its activities while a forest manager is in charge of day-to-day management. There are 10 volunteers and 3 permanent staff working within this organisation. They get income mainly from access fees, fines from defaulters and auction sales.

The macro and meso study context (forest/land use administration)

The Ministry of Forests and Fauna steers forest policy implementation, including coordination with allied ministries. Based in the capital city, it has provincial and divisional delegations and sub-divisional forestry and wildlife posts in descending administrative order. A Directorate of Inventories holds major responsibility in information management within the ministry. This responsibility is shared with the Agence Nationale D'Appui au Development Forestier (ANAFOR), a government agency that retains quasi-monopoly in technical services such as forest inventories, mapping and silvicultural services for the ministry. Within it, is another substructure specialised in mapping and remote sensing known as Centre de Télédétection et de Cartographie Forestière (CETELCAF). The Système Informatique de Gestion des Informations Forestière (SIGIF) of CETELCAF constitutes the main computerised information system. All of these systems were set up without the CDM in mind.

Forest administration services at the provincial, divisional and sub-divisional levels are basically involved in routine narrative reporting on the state of forests in their jurisdiction. Occasionally sketch/traced maps of concessions, protected areas and production forest areas are included in these reports. Inventories and management plans for these forest units constitute the main sources of detailed information on botany, forest characteristics and land use changes. 


\section{CDM forestry project data requirements (demand analysis)}

This section gives an overview of the evidence (data and information) required of the CDM process for forestry projects. Figure 1 summarises the CDM project cycle. It shows the links between the project on the ground (micro-level), the national level (macro) and the international institutions that verify and certify the projects. This implies information has to be carefully managed between the institutions in the right formats within the CDM process. However, we begin by briefly sketching the CDM forestry project requirements.

CDM forestry requirements

CDM projects are expected to meet a set of requirements prior to the issuance of certified emission reductions. These requirements are articulated in the Kyoto Protocol and in subsequent decisions taken during various Conferences and Meetings of

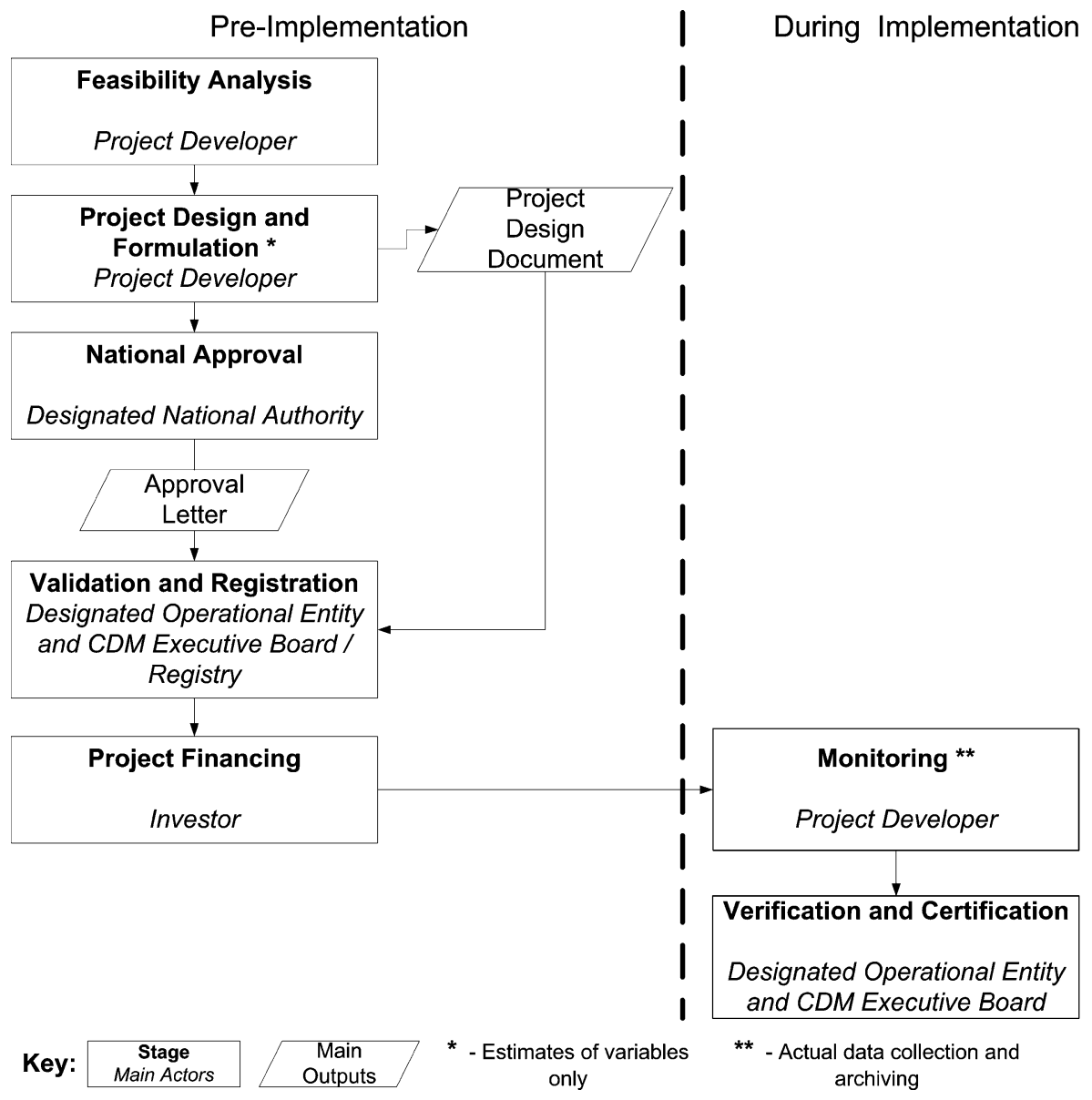

Fig. 1 Clean Development Mechanism project cycle 
Parties (Decisions 19/CP.9 and 14/CP.10). These requirements can be summarised under the following categories: eligibility, additionality, acceptability, externalities and certification.

\section{Eligibility}

Afforestation and Reforestation are the only forestry activities eligible under the current CDM rules during the first commitment period (2008-2012). Afforestation would mean planting trees on land that has not been forest for a period of at least 50 years (i.e. according to the host country definition of forest). Reforestation would mean planting trees on land that was not forest on 31 December 1989.

\section{Additionality}

Sequestration or emission reductions due to the project activities must be "additional" to any that would occur in the absence of the project (Paragraphs 18-22 of Decision 19/CP.9). In other words, holding everything else constant, would a project have happened in the absence of the offset crediting system? If yes, then the project is not additional; if no, then the project is additional (Trexler et al. 2006).

\section{Acceptability}

The Kyoto Protocol states that all carbon offset projects in developing countries are required to contribute to sustainable development (Articles 2.1 and 12.2). Host countries have to set criteria for sustainable development by which projects will be judged.

\section{Externalities (Environmental impact and leakage)}

Projects must demonstrate a clear strategy to deal with all socio-economic, cultural and environmental impacts that may arise from project implementation. Projects have to demonstrate how the negative impacts would be mitigated or countered. Project analysis must also show how they will address possible unplanned emissions that could occur outside project boundaries as a result of project activities (known as leakage).

\section{Certification}

The concreteness, measurability and long-term characteristics of the project will have to be checked independently by a third-party (i.e. a Designated Operational Entity) accredited by the CDM executive board. This takes place in two stages namely validation and verification (see Fig. 1). These processes enable project registration, and the issuance of Certified Emissions Reductions, for offset credits, respectively.

\section{Alternative non-CDM approaches}

Current ideas under discussion by UNFCCC regarding post-2012 Kyoto Protocol implementation suggest that a national, sectoral approach to forestry might be 
adopted, such as the concept of "Reduced Emissions from Deforestation and Degradation-REDD" which proposes the introduction of natural forest management into the Kyoto options (Santili et al. 2005). The REDD idea suggests a mechanism in which countries that elect to reduce national level deforestation to below 1980-1990 level would receive post-facto compensation, whilst they commit themselves to stabilise or further reduce deforestation in the future. This means national governments taking responsibility for meeting the reduction targets through a sectoral approach. The details as regards data requirements for this type of approach are not yet clear, since indeed the policy is only at the discussion stage, but it is clear that such an approach cannot be taken without rigorous planning and monitoring data; and since the approach is nation-wide rather than at project level, it is self-evident that an appropriate national information infrastructure will be needed as soon as a country elects to be part of this mechanism. The implications of this are taken up in the last section.

\section{Micro-level information}

Project developers have to provide verifiable evidence demonstrating adherence to all of the above-mentioned CDM rules in a Project Design Document (PDD). Appendix A of Decision 19/CP.9 specifies the content of the project design document for Afforestation and Reforestation projects, while appendix A of Decision 14/ CP.10 details simplified procedures for "small-scale projects"-i.e. producing $<8 \mathrm{Gg} \mathrm{CO}_{2} / \mathrm{yr}$.

Figure 2 represents a conceptual data model for CDM information management at the micro (project) level. It identifies the various data units needed and shows how they could contribute to the arguments for various criteria in the project design document. We derived the model from analysing the details written into various Kyoto/CDM decisions and publications (IPCC 2003; Decisions 19/CP.9; Decision 14/ CP.10). Information from approved methodologies such as methodology number AR-AM0001 for "reforestation of degraded land" in Guangxi, China and an analysis of methodologies reviewed within the CDM procedure so far by Kagi and Schoene (2005) are also used in the analysis.

The specifics of data and choices of what data to employ in arguments would depend on each project and its chosen methodology. For instance, a project can choose which of the five carbon pools they want to account for, hence some of the information in column 3 of Fig. 2 will not be relevant. Most projects have opted for above-ground tree biomass and below-ground biomass leaving soil, dead wood and litter optional. However, projects have to demonstrate that the excluded pool will not influence net carbon removal or increase as part of the baseline or project activity. This means they still require limited data for these pools to enable argumentation.

Looking at the categories of data displayed in Fig. 2, it is clear that a large proportion requires local level data (e.g. 1a, c, d, e, g; 2a,b; and 3a and possibly 3b). For although most methods in the Good Practice Guidance argue for a combination of default values, field measurements and model-based methods (IPCC 2003), the purpose and level of activity might influence the kind of data used. Project feasibility studies at an early stage may rely on default values and regional land use data for some steps, e.g. to determine whether the project qualifies as a small scale project or 


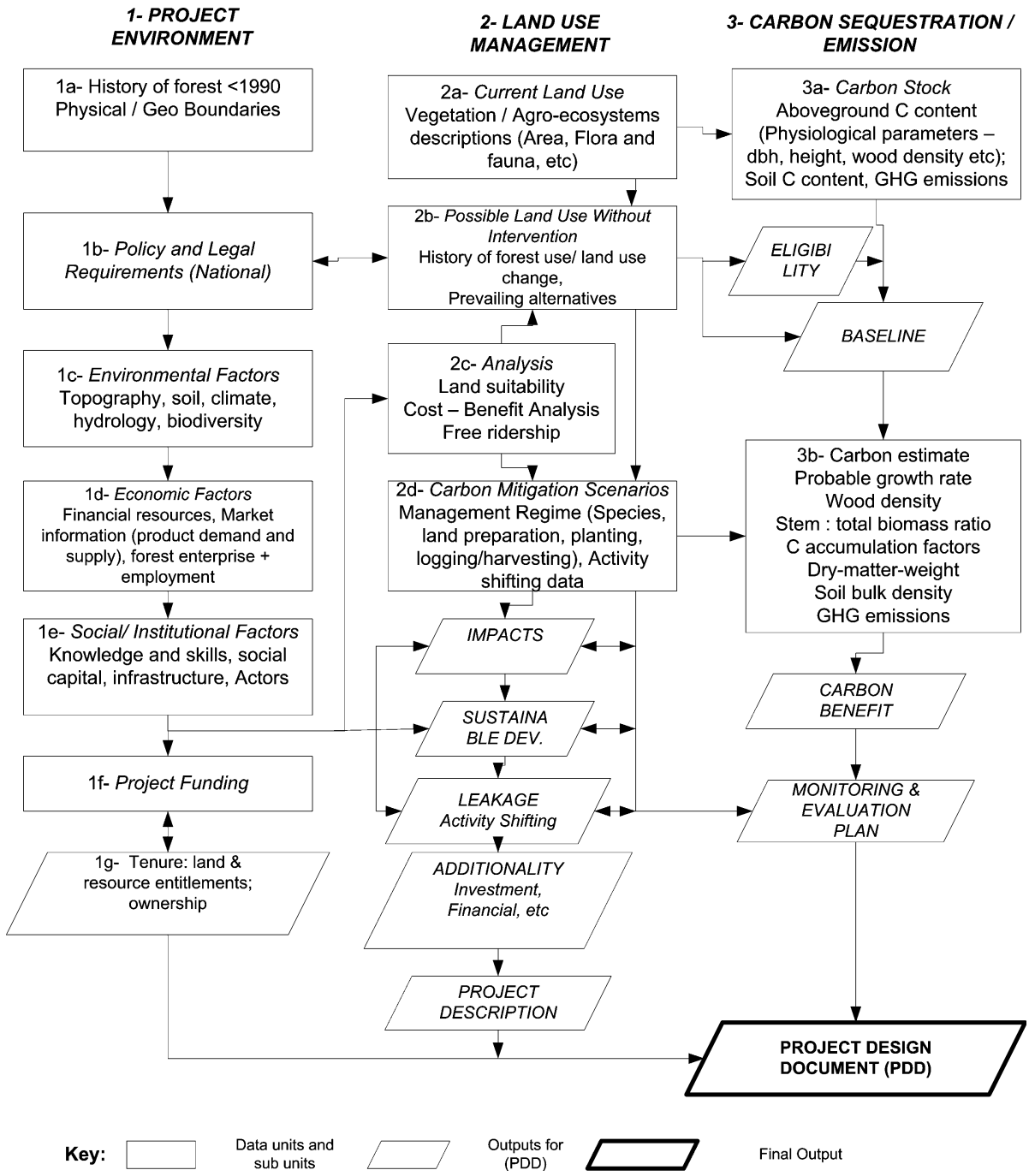

Fig. 2 Conceptual data model for CDM PDD preparation

not, but for many other steps local data are essential. Field measurements are in any case compulsory for monitoring normal and small-scale projects.

Murthy et al. (2006) found that costs of gathering such data would vary depending on the methodology used (there are four approved afforestation and reforestation methodologies and normal sized projects may also propose their own). For a 32,965 ha community forest project in India, they report costs of $\$ 1.2 / \mathrm{Mg} \mathrm{C}$ if default values are used; $\$ 2.8 / \mathrm{Mg} \mathrm{C}$ when modelling is used; and $\$ 7.0 / \mathrm{Mg} \mathrm{C}$ when crosssectional field studies are employed.

National (macro) and sub-national (meso) levels

Macro and meso-level data are not mandatory for CDM project development but can be supportive of carbon forestry project uptake and implementation. Current 
modalities and procedures stipulate two compulsory data types for project validation at national level, including criteria for the determination of sustainable development, and poverty criteria for community qualification for small-scale projects (Decision 19/CP.9).

The Good Practice Guidance report (IPCC 2003) provides three levels or 'tiers' as regards use of data. Tier 1 methods involve standard categories using default values based on IPCC factors stratified on a regional basis (temperate and tropical), while Tier 2 involves using more country-specific categories and carbon sequestration rates as opposed to those advanced by the Kyoto framework. Tier 3 involves model-based estimates requiring much more detailed data on the ground activity and other data. Country level data would include area-specific land use data and categories and allometric equations for specific agro-ecosystems and soil bulk density indices that may be beyond the expertise of project developers (Birdsey 2004; Brown 2002; Conant and Paustian 2004).

Some project experiences show that meso-level or national level data can be helpful for feasibility analysis and for estimating project baselines using tier 2 methods. For example, Murthy et al. (2006) used regional default data in estimating carbon project baselines in the Mancherial forest division in Andhra Pradesh, India. However, they also note that they could have obtained better results if regional land use records and afforestation trend data of the area were up to date and well organised.

The nature of leakage constitutes another important reason for macro and meso data generation support (Chomitz 2002; Tipper et al. 2002). Projects would have physical boundaries beyond which monitoring would be impracticable, hence would need regional and national data on land use activity shifts and market dynamics (forest product demand and supply) to support leakage monitoring.

\section{Supply analysis}

In this section we firstly examine data availability using a simple checklist approach. Checklists include data aspects in Fig. 2 for the micro-level and column 1 of Table 2 for meso- and macro-levels. Secondly, we discuss the entire information infrastructure capability in terms of Strengths, Weaknesses, Opportunities and Threats.

Data availability

\section{Micro-level data availability}

Table 1 summarises data availability in the two case-study communities. The available information in these communities is routinely collected as part of the community forests planning process (i.e. aspects of 1a, c, d, e, g; 2a; and 3a in Fig. 2). Some of this information could be used for further analysis on impact, baselines, leakage and other CDM requirements. Additional information would be needed to plan for carbon management. For example, community forest inventories were done mainly for timber species and for trees of diameter $>30 \mathrm{~cm}$. Carbon measurements would require multi strata data and also height and dry weight measurements in subplots for all species. Land use change information is also not available, but land tenure information is available as oral narratives. 
Table 1 CDM Micro-level data availability for Tinto and Bimbia Bonadikombo

\begin{tabular}{|c|c|c|c|c|c|c|}
\hline \multirow[t]{2}{*}{ Data type } & \multicolumn{3}{|l|}{ Tinto } & \multicolumn{3}{|c|}{ Bimbia Bonadikombo } \\
\hline & $\begin{array}{l}\text { Paper } \\
\text { data }\end{array}$ & $\begin{array}{l}\text { r Digital } \\
\text { data }\end{array}$ & Comments & $\begin{array}{l}\text { Paper } \\
\text { data }\end{array}$ & & Comments \\
\hline \multicolumn{7}{|l|}{ 1. Project circumstances } \\
\hline History of forest $<1990$ & $\mathrm{P}$ & $\mathrm{P}$ & Not documented & $\mathrm{P}$ & $\mathrm{P}$ & $\begin{array}{l}\text { Satellite images and } \\
\text { maps available from } \\
\text { MCBCC }{ }^{\mathrm{a}} \text { GIS lab } \\
\text { at a fee }\end{array}$ \\
\hline $\begin{array}{l}\text { Physical and geo } \\
\text { boundaries }\end{array}$ & $\mathrm{Y}$ & $\mathrm{N}$ & & $\mathrm{Y}$ & $\mathrm{Y}$ & \\
\hline $\begin{array}{l}\text { Current land/resource } \\
\text { ownership and } \\
\text { entitlements }\end{array}$ & $\mathrm{Y}$ & $\mathrm{N}$ & Partial & $\mathrm{Y}$ & $\mathrm{N}$ & Partial \\
\hline $\begin{array}{l}\text { Environmental factors: } \\
\text { topography, soil, } \\
\text { climate, hydrology, }\end{array}$ & $\mathrm{Y}$ & $\mathrm{N}$ & & $\mathrm{Y}$ & $\mathrm{N}$ & $\begin{array}{l}\text { Accessible in MCBCC } \\
\text { by application }\end{array}$ \\
\hline Biodiversity & $\mathrm{P}$ & $\mathrm{P}$ & Ibid & Y & $\mathrm{Y}$ & $\begin{array}{l}\text { Accessible at MCBCC } \\
\text { by application }\end{array}$ \\
\hline Financial resources & $\mathrm{Y}$ & $\mathrm{N}$ & & $\mathrm{Y}$ & $\mathrm{Y}$ & \\
\hline Product demand \& supply & $\mathrm{Y}$ & $\mathrm{N}$ & Incomplete & $\mathrm{N}$ & $\mathrm{N}$ & \\
\hline Forest related employment & $\mathrm{N}$ & $\mathrm{N}$ & & $\mathrm{N}$ & $\mathrm{N}$ & \\
\hline Social/institutional factors & $\mathrm{Y}$ & $\mathrm{N}$ & & $\mathrm{Y}$ & $\mathrm{N}$ & \\
\hline Knowledge and skills & $\mathrm{N}$ & $\mathrm{N}$ & & $\mathrm{N}$ & $\mathrm{N}$ & \\
\hline $\begin{array}{l}\text { Stakeholder description } \\
\text { 2. Land use management }\end{array}$ & $\mathrm{Y}$ & $\mathrm{N}$ & & Y & $\mathrm{Y}$ & \\
\hline Current land use & $\mathrm{Y}$ & $\mathrm{N}$ & & $\mathrm{Y}$ & $\mathrm{N}$ & \\
\hline $\begin{array}{l}\text { History of land } \\
\text { use change }\end{array}$ & $\mathrm{P}$ & $\mathrm{P}$ & & Y & $\mathrm{Y}$ & From MCBCC \\
\hline Land suitability & $\mathrm{P}$ & $\mathrm{P}$ & $\begin{array}{l}\text { Only indigenous } \\
\text { Knowledge }\end{array}$ & $P$ & $\mathrm{P}$ & $\begin{array}{l}\text { Only indigenous } \\
\text { knowledge }\end{array}$ \\
\hline Deforestation & $\mathrm{N}$ & $\mathrm{N}$ & & $\mathrm{N}$ & $\mathrm{N}$ & \\
\hline Afforestation/reforestation & $\mathrm{N}$ & $\mathrm{N}$ & & $\mathrm{P}$ & $\mathrm{P}$ & Tree planting data \\
\hline $\begin{array}{l}\text { Records of cost and } \\
\text { benefits of forest activities }\end{array}$ & Y & $\mathrm{N}$ & Only in part & Y & $\mathrm{Y}$ & \\
\hline $\begin{array}{l}\text { Free ridership tendencies } \\
\text { 3. Carbon sequestration/emis }\end{array}$ & $\begin{array}{l}\mathrm{N} \\
\text { sion }\end{array}$ & $\mathrm{N}$ & & $\mathrm{N}$ & $\mathrm{N}$ & \\
\hline 3a. Soil C content & $\mathrm{N}$ & $\mathrm{N}$ & & $\mathrm{N}$ & $\mathrm{N}$ & \\
\hline $\begin{array}{l}\text { Above ground } \mathrm{C} \\
\text { diameter, dry weight, etc }\end{array}$ & $\mathrm{P}$ & $\mathrm{P}$ & $\begin{array}{l}\text { Was done only } \\
\text { for valuable } \\
\text { timber } \\
\text { species } \\
\text { of diameter } \\
\text { mostly }>30 \mathrm{~cm}\end{array}$ & $P$ & $P$ & $\begin{array}{l}\text { Trema-database } \\
\text { with measurements } \\
\text { including trees }<30 \mathrm{~cm} \\
\text { obtainable from } \\
\text { MCBCC (Partial) }\end{array}$ \\
\hline Species inventories & $\mathrm{N}$ & $\mathrm{N}$ & & $\mathrm{Y}$ & $\mathrm{Y}$ & \\
\hline $\mathrm{C}$ accumulation factors & $\mathrm{N}$ & $\mathrm{N}$ & & $\mathrm{N}$ & $\mathrm{N}$ & \\
\hline
\end{tabular}

a Mount Cameroon Botanic Gardens and Conservation Centre

$\mathrm{N}=$ Not available; $\mathrm{P}=$ Partially available $; \mathrm{Y}=$ Available

Both communities have a limited amount of available data in digital format. More digital information is available from Bimbia, but mostly in the keeping of the Mount Cameroon Biodiversity and Conservation Centre. The Centre inherited digital geographic data of the boundaries, biological inventories and land use data of Bimbia from Mount Cameroon project and retains them to date. The community needs to apply to the Conservator of the Centre to have access to the data. For 


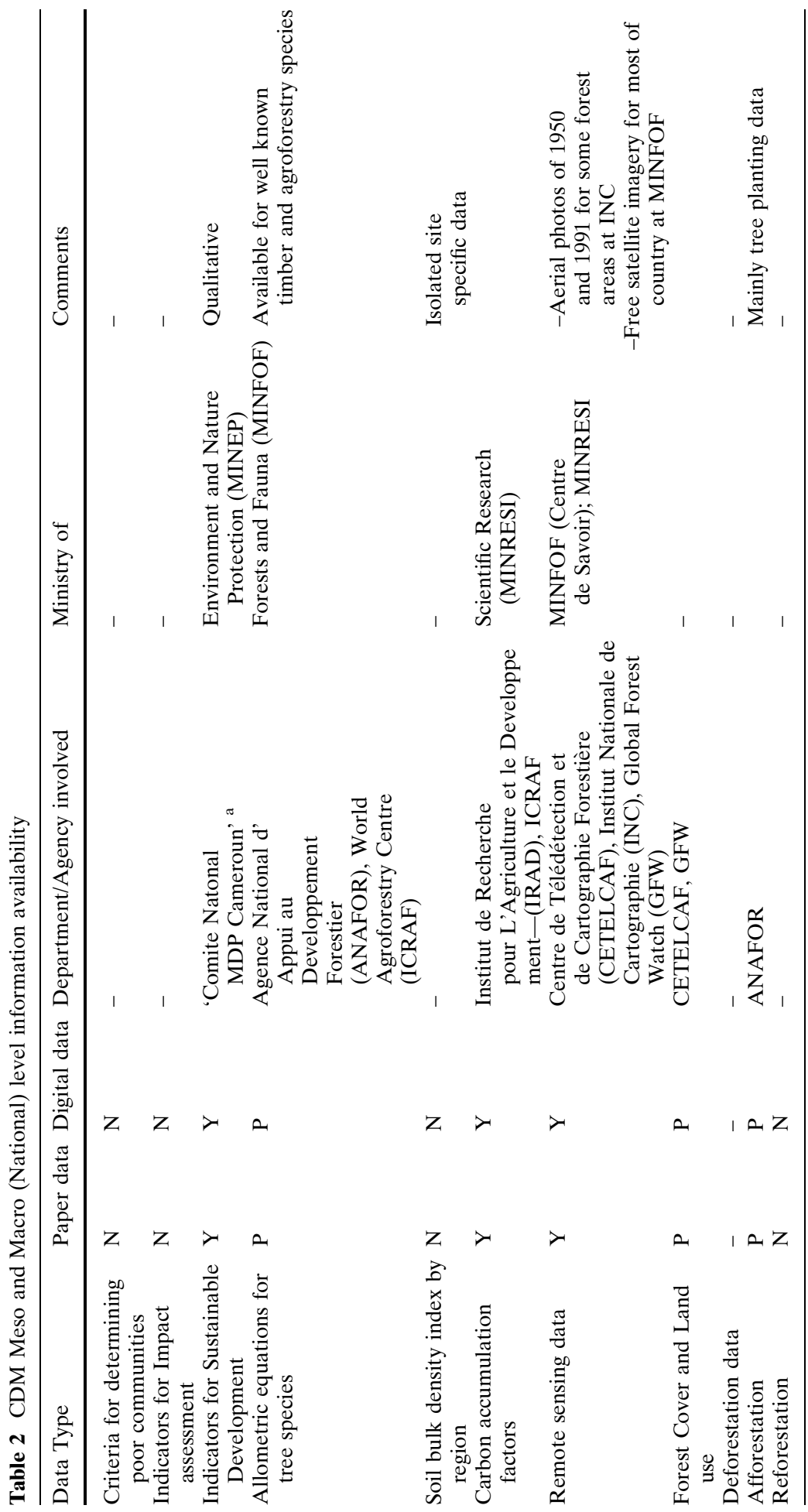




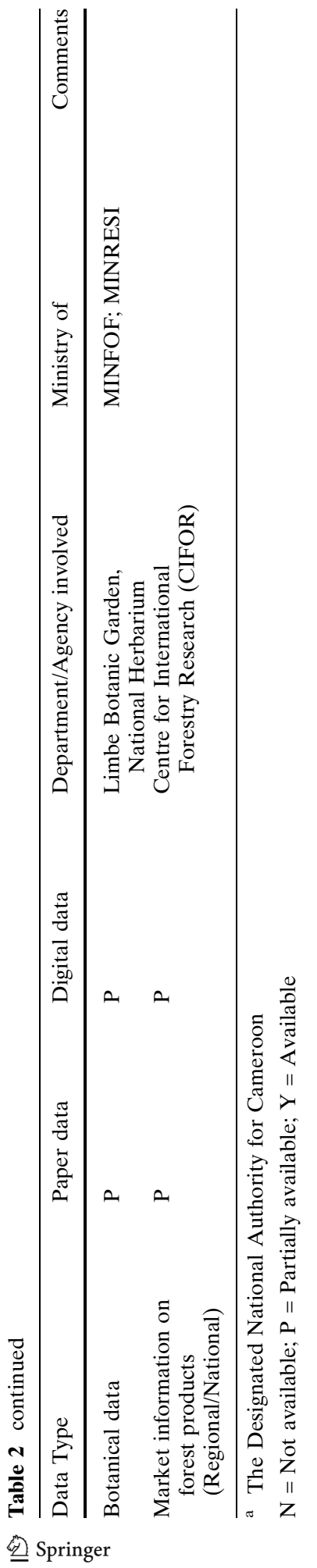


carbon forestry to work, this information would have to be kept and updated regularly by the community and also shared with the institution responsible for verifying carbon changes.

The quality of data available in both communities is good. The facilitating NGOs ensured good quality expertise, planning and quality control during the data collection and analysis process. Experts from the Sub-Directorate of Community Forestry in the Ministry of Forests and Fauna validated the forest inventory process and inventory results of both communities.

\section{Macro-level data availability}

Table 2 summarises the macro-level availability of data in Cameroon that is required to support CDM project uptake and implementation. Relevant information is found in very many ministries, departments, government agencies and NGOs, but it is patchy, area-specific, project based and not the result of mainstream procedure of government data collection interventions.

Access rules vary between the meso and macro data items according to the institutional policies of each of the holders or producers of the data. For example, aerial photos and maps at the Institut National de Cartographie are paid for, while NGO projects such as Global Forest Watch would grant image data free of charge.

Data quality is also varied because different institutional values, sampling methods and purposes apply to data sets. Though common prescriptions for management inventories exist (ONADEF, 1992a, b, c), no common verification and validation procedures exist. For example, geographic/remotely sensed data and information at Centre de Télédétection et de Cartographie Forestière (CETELCAF), Ministry of Forests and Fauna (MINFOF), Global Forest Watch (GFW) and Institut National de Cartographie (INC) (Fig. 2) on land use, land cover and forests have different mathematical, thematic and attribute accuracy levels. The generally poor data availability in the LULUCF land use and forestry environment in Cameroon is the result of a multiplicity of factors. A detailed analysis of these factors across scales is given in the next section.

SWOT analysis of land use and forestry information infrastructure

Table 3 summarises the Strengths, Weaknesses, Opportunities and Threats (SWOT) for the forestry information infrastructure across the levels. It also proposes potential strategies for its enhancement. We elucidate on these dimensions in the ensuing paragraphs.

\section{Strengths}

Strong civil society contributions. NGOs have greatly influenced the forestry information infrastructure in Cameroon at all levels. Most communities currently managing community forests including Tinto and Bimbia, have received technical and financial support from NGOs or bilateral conservation projects. The Tinto community received help from Living Earth Foundation between 1999 and 2003 while Bimbia received assistance from the Mount Cameroon Project between 1996 and 2004. In Tinto a $10 \%$ inventory was done as required by community forestry regulations alongside socio-economic studies and management planning. In Bimbia, 

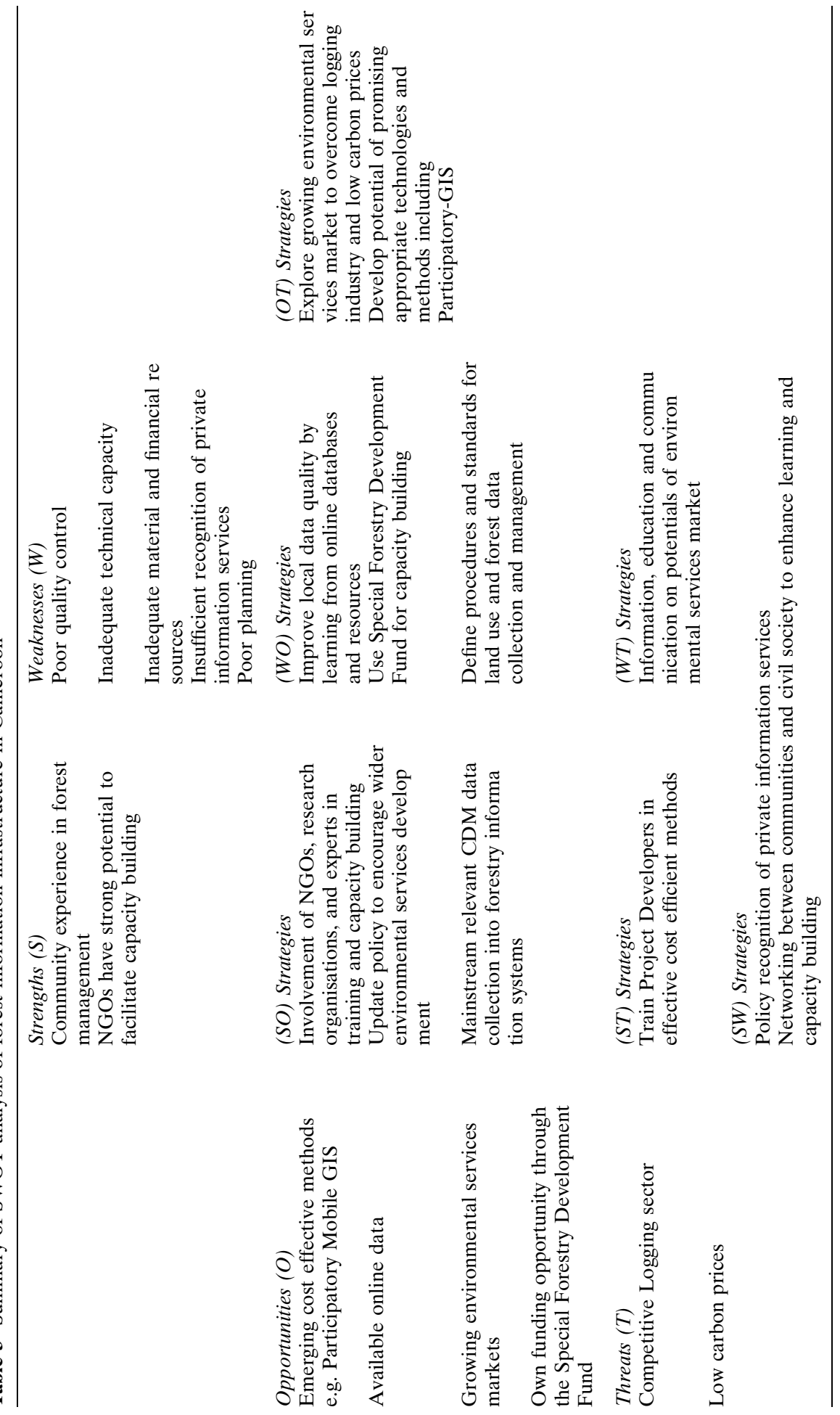

望 Springer 
Mount Cameroon Project did more, it developed a database of the Cameroon mountain forest area called Trema. It consists of geo-referenced forest inventory database with 20,000 data records from approximately 300 forest samples. It has built in functions to derive indices of 'bioquality' and can be easily modified using additional field information and regression equations to serve carbon management purposes (EcoSecurities 2002). Table 2 also shows that a great deal of regional and national level information is available from NGOs. Experience in carbon project development in other developing countries has shown that NGO support with providing technical skills in data gathering is important for project uptake and development (Tipper et al. 2002).

Experience in community forest inventories. Developments in community forestry since 1994 have been helpful in improving information availability at the micro-level. McCall and Minang (2005) show that communities improved their information systems, knowledge and skills significantly during community forestry planning. For example, the Tinto and Bimbia communities learned how to carry out participatory forest inventories because it is a sine qua non for community forestry in Cameroon. Such skills would be useful for carbon forestry monitoring in terms of reducing costs. Zahabu (2006) shows that using community members (with minimal supervision) to carry out carbon inventory field measurements in Tanzania (at between $\$ 2-8 / \mathrm{ha}$ / year) would reduce costs by between 70 and $50 \%$ compared to hiring professionals (at $\$ 15 / \mathrm{ha} / \mathrm{yr}$ ), and demonstrates that such community measurement can easily be carried out, delivering accurate estimates of carbon stock. The training and exposure to these measurement methods also helps the community understand the value of trees. This can motivate tree planting and hence provide a multiplier effect on carbon forestry. Further evidence of the abilities of communities to effectively manage data gathering on carbon stocks is presented by the Kyoto: Think Global, Act Local Project (www.communitycarbonforestry.org).

\section{Weaknesses}

Inadequate resources. Great lack of knowledge in data management is observed at all levels, and the poor financial resources at all levels impede access to trained resource persons, in-service training and material and technical resources.

Murthy et al. (2006) cite costs for establishing baselines and project formulation of $\$ 1.25 / \mathrm{ha} / \mathrm{yr}$ for a 32,965 ha community forestry project. These costs are expected to increase for much smaller forests. Zahabu (2006) cites actual carbon inventory costs from three small community forests in Tanzania ranging from $\$ 2.5-21 / \mathrm{ha} / \mathrm{yr}$. On the other hand, total incomes for the Tinto and Bimbia community forests for 2005 were $\$ 10150$ (5 million CFA franc) and $\$ 30200$ (15 Million CFA franc), respectively. The Bimbia community was running at a deficit of approximately $\$ 3000$ at the end of the same period. Considering the above-mentioned costs and the financial resources of these communities, it may be difficult to begin CDM project development in these forests without outside help.

Technical resources such as satellite images, Global Positioning Systems (GPSs) and tree height measurement instruments would be helpful in providing information required for baseline estimation and eventual monitoring. Free satellite image data is obtainable from the Ministry but communities would need to hire expertise for analysis. Bimbia has one GPS that can allow them to map current land use, whereas Tinto has only a compass that can be useful for inventories. 
The human resources required for related baseline analysis and monitoring are currently limited in both communities. A total of 14 Bimbia and 11 Tinto community members received training from Living Earth and Mount Cameroon Project, respectively on timber inventories during the process of developing the simple management plans. The main skills acquired included doing physiological measurements (tree heights, dbh), using the compass and or the GPS, tree identification and laying out sample plots and transects. But the skills required for carbon estimation are more complex, including biomass estimation, using allometric equations, root biomass estimation, destructive sampling, etc. These technical carbon estimation skills are absent in both communities.

Skills for financial and investment analysis are absent in these communities. One of the staff in Bimbia has basic undergraduate knowledge in cost-benefit analysis but this is not enough. The community needs to hire such services at high costs. In Tinto no one has the required skills and knowledge.

Besides the lack of knowledge and skills, there are shortages in staffing (skilled and unskilled) to enable adequate data collection at project level and within government institutions. In Bimbia for instance, the ratio of staff to forest area is 1:285 ha. In Tinto, the ratio will be 1:120 ha if the manager and the 11 trained persons are taken into account. In the Southwest Province where both communities are located, the ratio of Ministry of Forests and Fauna staff to forest area is about 1:15,000 ha (Brunner and Ekoko 2000). These resources are grossly inadequate to meet the high carbon forestry information demands.

Poor planning and coordination. Relevant forest and land use data collection, storage and distribution are extremely inadequate. No systematic data collection procedure with complete coverage of agro-ecological zones exists in the country. A good part of existing data is from conservation projects at specific sites, at varied times and with varied methods (see Table 2). The creation of the Système de Gestion D'informations Forestière at the Centre de Télédétection et de la Cartographies Forestière was a first attempt at coordination. But this system contained mainly boundary, limited inventory and harvest data from timber concession areas. An attempt at making a systematic nationwide mapping of agro-ecological zones came with the indicative land use framework (Plan de Zonage) in 1995. But this ended up covering slightly less than $30 \%$ of the country.

For data generation to be effective in serving wider sustainable development objectives including terrestrial carbon mitigation, it has to be systematic. To serve the development of default factors as well as Tier 3 methods, its spatial resolution must be planned to cover all five agro-ecological zones of Cameroon as well as internal variability within these zones (IPCC 2003). Birdsey (2004) recommends a temporal resolution of 5 years in order to capture land use change and management impacts for carbon forestry.

To illustrate the difference between a systematic approach and that existing in Cameroon we sketch the United States Department of Agriculture (USDA) Forest Service, Forest Inventory and Analysis (FIA) program as described in Birdsey (2004). They conduct a continuous inventory of forests, providing periodic estimates of area, timber volumes, tree biomass and wood products. Data are collected in many states every year, with all of the sample plots scheduled for measurement over a period of 5-10 years. A multiphase sampling design is used allowing for detailed ground measurements in about 150,000 permanent field locations. It might be costly for a non-annex 1 country to carry out such detailed and intensive ecosystem studies. 
Inadequate recognition of private information initiatives. Current practice does not encourage private initiative in information systems development. Data and information products from non-government sources are unlikely to be considered legitimate for various purposes even though they may be more up-to-date and accurate. For example, certified forest boundaries hand-traced on 1983 topographic map sheet cuttings by the Institut National de Cartographie although no field visits were used, in preference to recent community-produced Geographic Information System (GIS) maps, for the Tinto community forest application approval by the Minister of Forests and Fauna (McCall and Minang 2005). Issues of this sort discourage information systems development and data collection at various levels, especially when large investments in time and money are involved.

Local NGOs and consultants argue that recognition of private information services in other land use and forestry activities would encourage investments that would benefit carbon forestry though they may not be worthwhile for carbon forestry alone.

\section{Opportunities}

Emerging cost-effective methods. Participatory Geographic Information Systems, notably mobile Geographic Information Systems (GIS) based methods are proving to be simple, accurate enough and cheaper for community carbon measurements and monitoring in Senegal, Tanzania, Nepal and India. Experiments using hand-held computers with GIS capability and attached Geographic Positioning Systems (GPS), are enabling villagers with between 4-7 years of basic education to successfully map forests, measure and digitally enter biomass data (dbh, height, species name, etc) and relocate permanent sampling plots successfully after just 1-3 days of training (Skutsch 2005; Verplanke 2004). Carbon inventory costs were reduced by about $50 \%$ (compared to employing professionals) while rigorously respecting the methodological guidelines of the IPCC. Technologies of this type could be helpful in building on current community experience in Bimbia and Tinto where in the communities had been trained in the use of GPS devices, compasses and aerial photo interpretation. These methods enable simplification of the complex CDM rules at local level through basic training. It also enhances the utility of local knowledge and improve the acceptability and sharability of information within the CDM framework. Costs of these gadgets are falling very fast, thereby improving prospects for increased use in poor communities like Tinto and Bimbia.

Available online data. Section 4.1 indicates that remote sensing and GIS data for land use, forest cover is not adequately available and accessible for use by potential project developers in Cameroon. One way of mitigating this problem is through the use of open source databases. Satellite imagery and other geographic data can increasingly being accessed free of charge on the internet from databases. A relevant example includes online access to Multi-Spectral Scanner (MSS), Landsat Thematic Mapper (TM) and Enhanced Thematic Mapper (ETM) satellite imagery and digital elevation models, at the Global Observation of Forest Cover (GOFC) Project website. While these sites may not provide all the information, they can greatly contribute both to carbon baselines establishment and monitoring data within the $\mathrm{CDM}$ and to reduced emissions from deforestation and degradation. As in the case of Bimbia, a NGO or academic institution may have to play the role of facilitator, providing the technical skills and resources required to manage this data. 
Budding environmental services markets. The potential growth of markets for other environmental services including watershed management and biodiversity offers great opportunities for the development and application of a multipurpose forest data infrastructure (Grieg-Gran et al. 2005; Pagiola et al. 2005). If integrated forest management including all services is adopted, key forest information could be used for carbon, biodiversity and watershed management and other ecological services and hence reduce the cost per unit of data collection and management. In aggregation, the potential revenue may provide sufficient motivation for investments into adequate data infrastructures that carbon alone would not justify.

\section{Threats}

Competitive logging sector and low carbon prices. Given lucrative timber market prices, logging has a competitive edge over carbon as a forest use, thereby impeding investments into carbon development including data collection and information management. Tommich et al. (2002) suggest a world price of $\$ 25$ per $\mathrm{Mg} \mathrm{C}$ to shift incentives from forest conversion (including logging) to conservation in Indonesia, while current CDM prices are only between $\$ 3$ and 5/Mg C.

\section{Strategies}

Observations emerging from the above analysis point to a number of potential strategies (see Table 3). Salient proactive policy strategic issues in Table 3 such as capacity building through training, promoting networking and institutional development; and embracing hi-tech, the internet and the market mechanisms driving the commoditisation of environmental services are sketched in the conclusions.

\section{Conclusions}

International policy information specifications for certification or environmental service payments under the CDM cannot easily be met in data scarce environments, thereby limiting the participation of many developing countries in such schemes. This paper firstly examined the need for, and explored the structure of, a supportive data infrastructure needed for CDM implementation (Demand). Next, it reviewed the appropriateness of current forestry data infrastructures in Cameroon to supply the required information.

We confirm that data demands for CDM projects far exceed the supply capacity of communities at the micro, meso and macro-levels (see Tables 1,2). This is also true for small-scale project conditions, implying that current slow trends in CDM project uptake and development are likely to continue if information demands are not revised at the international level. Nevertheless, table 3 presents a summary of the strengths, weaknesses, opportunities, and threats to the development of an enabling CDM implementation data supply infrastructure. More importantly it presents a set of potential strategies that would be required to support CDM project uptake and implementation. They can be grouped into a number of general categories of required practical policy implications. 
Direct measures for enhancing data infrastructure for CDM

Firstly, engaging in micro (project) level capacity building is urgent if carbon forestry project uptake is to be improved in Cameroon. Such a programme must actively target training in good practice carbon data gathering techniques and monitoring methodologies as described in the Good Practice Guidance Report (IPCC 2003), as well as growing and emergent approaches such as the participatory GIS being applied in Tanzania, Nepal and Senegal (Skutsch 2005; Verplanke 2004). Helping with the acquisition of the appropriate data collection technology could also be included in such a scheme. One way of achieving this would be to develop a number of "centres of excellence" or networks of expertise that can systematically provide training nationwide to aspiring project developers.

Another option could be to actively engage interested NGOs, academic institutions and consultants to partner with project developers and provide such training and capacity building. This approach has been helpful in carbon project development in other developing countries-for example, the Scolel Te project in Mexico was supported by Ambio and the Edinburgh Centre for Carbon Management (Corbera 2005); Mount Elgon and Kibale National Parks reforestation projects in Uganda received Face Foundation support (Jindal et al. 2006); and the Centre for Ecological Sciences in Bangalore is providing leadership in supporting CDM forestry projects with local partners in several places in India (e.g. Murthy et al. 2006). The strategic role played by NGOs in community forestry uptake following similar capacity concerns with the community forest acquisition procedures also supports a greater role for NGOs in facilitating CDM forestry projects.

The "Comité National Mecanisme de Developpement Propre (MDP) Cameroun", Cameroon's Designated National Authority that has the mandate to promote project uptake, could solicit funding for such a capacity building programme from the Special Forestry Development Fund in the Ministry of Forestry and Fauna. This special fund is an initiative that enables a proportion of forest revenues to be ploughed back into forestry development. The example of a national forestry financing fund called FONAFIFO in Costa Rica (Subak 2000), which helped initiate local carbon management projects within agroforests, remain one of the best examples of how government funds can be used to motivate project uptake and implementation. They could also tap from multilateral Kyoto capacity building funds. Examples include the Capacity Development for Clean Development Mechanism at the UNEP Collaborating Centre on Energy and Environment and UNIDO's CDM Capacity Building for Francophone African countries.

Secondly, enhancing meso and macro level data infrastructure would complement micro-level CDM land use, forest cover and leakage data. Necessary changes could include developing standard procedures and norms for forest data collection at all levels for various forest types, including the recognition of the role of private sector in the process. Such a standard could tap from the rich International Standards Organisation (ISO) literature (e.g. the 8000, 9000 and 19000 series) and from the experiences of timber certification (Molnar 2004).

Clearly defining roles and responsibilities for planning and coordination in agriculture, forestry and land use information management following well developed examples such as the United States Department of Agriculture Forest Inventory and Analysis program (Birdsey 2004) would also be important. 
General implications

\section{As regards $C D M$}

Firstly, more attention should be given to supporting an enabling national policy framework, especially the development of an enabling data support infrastructure. Our study shows that the absence of an enabling data support infrastructure constitutes a significant impediment for CDM project uptake in poor countries, especially in Africa where the uptake and development of CDM projects is slowest (Jindal et al. 2006). It shows that national level data such as land use, soil bulk density or allometric equations and more will be required as they are beyond the skills of most project developers, and are needed to support the Tier 2 methods as required in the Good Practice Guidance for Land Use, Land Use Change Forestry projects (IPCC 2003).

Secondly, research into new, effective and appropriate methods for planning and monitoring CDM forestry projects, such as mobile GIS, participatory inventory techniques and cost effective remote sensing techniques are required to speed up project uptake and implementation in host countries. This would also mean reinforcing technology transfer mechanisms within CDM implementation processes. This needs to be built into the global CDM capacity building strategy if project implementation is to go ahead in poor countries like Cameroon that are currently lagging behind.

Finally, this study suggests that current CDM afforestation and reforestation information demands as currently designated are almost impenetrable for local communities and also present a number of cross-scale barriers to project adoption. Moreover, it demonstrates that proactive capacity building and data support infrastructure policy development are needed in developing countries as a route to enhancing project uptake.

\section{As regards future forest policy options under UNFCCC}

As noted earlier, it is possible that CDM policy regarding forestry in developing countries may be supplemented, or even superceded, in the post-2012 period by an approach in which the whole forest sector, or even the whole land use sector, of a country is treated as a unit. The main advantage of this policy shift is that it would greatly widen the scope of investments in forestry to contribute to mitigation of climate change, since not only afforestation and reforestation, but also forest management and efforts to reduce rates of deforestation could be included. But such an approach brings with it massive requirements for data; border to border, continuously monitored forest inventory information would be needed so that the country could weigh forest gains in some areas against losses in others, since only the absolute gains in forest would be rewarded. Skutsch et al. (2006) point to the heavy reliance on remote sensing data for implementing Reduced Emissions from Deforestation and Degradation (REDD) in this regard. This would include serial remote sensing images from a given base period/year, land use, land cover, forest area and texture changes and ground truth data for all these categories. Thus, if REDD is adopted, meso and macro-level data would become an absolute necessity for carbon forestry implementation in non-Annex 1 countries, to a much greater 
extent than is now the case for CDM, for which at present meso and macro-level data is seen as merely supportive.

In addition, highly detailed, systematically collected micro-data is likely to be needed, for validating remotely sensed estimates of degradation and to some extent deforestation (i.e. as ground truth) within the REDD framework in the future. Moreover, if any sort of internal reward system is to be developed, micro-level data will be needed so that incentives can be provided for the various stakeholders who are responsible for the reductions in deforestation, through a payment for environmental services system for example (Trines et al. 2006). The participatory approaches to carbon stock assessment by communities themselves, which were developed in the first instance in the context of CDM, could here be of immense importance.

Acknowledgements We are grateful to the Directorate General for Development Cooperation (DGIS) of the Ministry of Foreign Affairs and International Institute for Geo-Information Science and Earth Observation (ITC), The Netherlands for providing the funding and facilities that enabled this study. We also thank Hans Bressers, University of Twente, for comments on earlier drafts of this paper. Our gratitude also goes to three anonymous referees whose extensive comments have greatly helped this paper.

\section{References}

Birdsey R (2004) Data gaps for monitoring carbon in the United States: an inventory perspective. Environ Manage 33:S1-S8

Brown S (2002) Measuring carbon in forests: current status and future challenges. Environ Pollut 116:363-372

Brunner J, Ekoko F (2000) Cameroon. In: Seymour FJ, Dubash NK (eds) The right conditions: The World Bank, structural adjustments and forest policy reform. World Resource Institute, Washington DC

Chomitz KM (2002) Baseline, leakage and measurement issues: how do forestry and energy projects compare? Climate Policy 2:35-49

Conant RT, Paustian K (2004) Grassland management activity data: current sources and future needs. Environ Manage 33:467-473

Corbera E (2005) Interrogating development in carbon forestry activities: a case study from Mexico. Dissertation, University of East Anglia

Dalal-Clayton B, Dent D, Dubois O (2003) Rural planning in developing countries: supporting natural resource management sustainable livelihoods. Earthscan, London

EcoSecurities (2002) Evaluation of the potential for developing a carbon programme in the Cameroon Mountains Region. Report for the Cameroon Mountain Conservation Foundation. EcoSecurities, Oxford

Grieg-Gran M, Porras I, Wunder S (2005) How can market mechanisms for forest environmental services help the poor? Preliminary lessons from Latin America. World Development 33:15111527

IPCC-Inter-governmental Panel for Climate Change (2003) Good practice guidance for land use, land-use change and forestry. Institute for Global Environmental Strategies (IGES), Kanagawa

Jindal R, Swallow B, Kerr J (2006) Status of carbon sequestration projects in Africa: potential benefits and challenges to scaling up. Working Paper No. 26. World Agroforestry Centre, Nairobi

Kagi W, Schoene D (2005) Forestry projects under the CDM: procedures, experiences and lessons learned. FAO forestry and climate change working paper 3. Food and Agriculture Organisation (FAO), Rome

Lewis PJ (1994) Information systems development. Pitman, London

McCall MK, Minang PA (2005) Assessing participatory-GIS for community-based natural resource management: claiming community forests in Cameroon. Geogr J 171:340-356 
Molnar A (2004) Forest certification and communities. Int For Rev 6:173-180

Morales J (2004) Model driven methodology for the design of geo-information services. Dissertation, University of Twente

Murthy IK, Hegde GT, Sudha P, et al (2006) Methodological issues in developing community forestry greenhouse gas emissions mitigation project in Mancherial forest division of Andhra Pradesh, India. Environ Sci Policy 9:525-537

ONADEF-Office NAational du DEveloppement Forestier (1992a) Normes d'inventaire d'aménagement et de pré-investissement. Yaoundé

ONADEF- Office NAational du DEveloppement Forestier (1992b) Normes de stratification forestière du territoire pour une cartographies au 1/50000. Yaoundé

ONADEF- Office NAational du DEveloppement Forestier (1992c) Normes de vérification des travaux d'inventaire de reconnaissance, d'aménagement et de pré-investissement. Yaounde

Pagiola S, Arcenas A, Platais G (2005) Can payments for environmental services help reduce poverty? An exploration of the issues and the evidence to date from Latin America. World Dev 33:237-253

Pfaff ASP, Kerr S, Hughes RF, et al (2000) The Kyoto protocol and payments for tropical forest: An interdisciplinary method for estimating carbon-offset supply and increasing the feasibility of a carbon market under the CDM. Ecol Econ 35:203-221

Santili M, Moutinho P, Schwartzman S, et al (2005) Tropical deforestation and the Kyoto Protocol: an editorial essay. Climate Change 71:267-276

Skutsch MM (2005) Reducing carbon transaction costs in community based forest management. Climate Policy 5:433-443

Skutsch MM, Bird N, Trines E et al (2006). Clearing the way for reducing emissions from tropical deforestation. Environ Sci Policy (Forthcoming)

Strauss A, Corbin J (1990) Basics of qualitative research: Grounded Theory, procedures and techniques. Sage, Newbury Park

Subak S (2000) Forest protection and reforestation in Costa Rica: evaluation of a Clean Development Mechanism prototype. Environ Manage 26:283-297

Tipper R, Carr R, McGhee W (2002) Guidance on baseline methodologies and crediting periods for LULUCF projects in the CDM. Edinburgh Centre for Carbon Management, Edinburgh

Tommich TP, de Foresta H, Dennis R et al (2002) Carbon offsets for conservation and development in Indonesia? Am J Alternative Agric 17:125-137

Trexler MC, Broekhoff DJ, Klosloff LH (2006) A statistically driven approach to offset-based GHG additionality determinations: what can we learn? Sustainable Dev Law Policy 6:30-40

Trines E, Hoehne N, Jung M et al (2006) Integrating agriculture, forestry, and other land use in future climate regimes: methodological issues and policy options. Report number 500102002. Netherlands Climate Change Scientific Assessment and Policy Analysis Programme (WAB), Bilthoven

Urquhart C (2001) An encounter with Grounded Theory: tackling the practical and philosophical issues. In: Trauth EM (ed) Qualitative research in IS: issues and trends. IDEA, Hershey

Verplanke J (2004) Combining mobile GIS and indigenous knowledge in community-managed forestry. In: Proceedings of the 3rd annual URISA Public Participation GIS (PPGIS) Conference, University of Wisconsin, Madison, 18-20 July 2004

Weihrich H (1982) The TOWS matrix — a tool for situational analysis. Long Range Planning 15:6776

Zahabu E (2006) Kitulangalo forest area, Tanzania. In: Murdiyarso D, Skutsch M (eds) Community forest management as a carbon management option: case studies. Centre for International Forestry Research, Bogor 